\title{
Incorporating ecological requirement into reservoir storage capacities design for adaptation to climate change
}

\author{
Chunxue $\mathrm{Yu}^{1,2, a}$, Xin'an Yin ${ }^{3, b}$, Zhifeng Yang ${ }^{2,3, c}$ and Zhi Dang ${ }^{1, d}$ \\ ${ }^{1}$ School of Environmental Science and Engineering, South China University of Technology, \\ University Town, Guangzhou, China \\ ${ }^{2}$ Research Center for Eco-Environmental Engineering, Dongguan University of Technology, \\ Dongguan, China \\ ${ }^{3}$ State Key Laboratory of Water Environmental Simulation, School of Environment, Beijing Normal \\ University, Beijing, China \\ ayuchunxue121@163.com, byinxinan@bnu.edu.cn, czfyang@bnu.edu.cn, ${ }^{\mathrm{d}} \mathrm{ch}$ zdang@scut.edu.cn
}

Keywords: Reservoir storage; Ecological requirement; Optimization model; Climate change. Abstract. Reservoir problems contain inherent uncertainty. The random nature of reservoir inflow is one of most important characteristic of determining the storage capacity of eco-friendly reservoir. However, previous eco-friendly reservoir storage requirement are generally derived from observed or synthetic flows and have rarely been determined by future flows under climate change. Here an optimization model is used in the design of the capacity of reservoir under future climate change to identify optimal trade-offs between two objectives: the maximization of the reliability and the minimization of the hydrologic alteration. The latter is evaluated considering different ecological requirement policies. There are three steps in the proposed model: (1) weather generator module is used to generate feasible future climate conditions, (2) VMOD model is adopted as the hydrological simulation module to generate flows from those future weather conditions, and (3) reservoir optimization module is employed to determine the optimal reservoir storage capability with different climate change conditions under different ecological requirement policies. Based on the results of various optimizations, it becomes possible to identify the most advantageous design alternatives to realize the reservoir project. It was found that the use of different storage capacity can enhance sufficiently both the water supply reliability and reduce hydrologic alteration.

\section{Introduction}

Reservoirs are the most important elements of complex water resource systems. They are used for spatial and temporal redistribution of water quantity and quality, and enhancing water's ability to generate hydropower. By building the dam, storage created may be used for flood control, water conservation (municipal, industrial, and agricultural water), navigation, and recreation [1, 2, 3]. However, the construction of reservoirs has greatly changed the natural flow regime of rivers, leading to the degradation of river ecosystem $[4,5,6]$. The design of eco-friendly reservoirs has attracted more and more attentions $[7,8]$.

In its simplest form, the ecofriendly reservoir analysis problem is always stated as: how large does the reservoir storage need to be to provide for a given demand with an acceptable level of reliability and environmental protection? This problem is known as determination of storage capacity for an eco-friendly reservoir. This is one of the main activities within the reservoir design procedure $[9,10]$. The authors have focus on the optimal sizing of a run-of-river small hydropower plant considering both environmental and economic targets [11]. Yin et al. (2015) have discussed the suitable range of reservoir storage capacities under different satisfaction degree of environmental flow provision [10].

In much of the existing and quite limited research, the current reservoir storage capability only including ecological requirement are used to determine how large the reservoir need. They usually might use the observed historical or synthetic inflows to evaluate the tradeoff among the various demands (flood control, irrigation and environmental requirement). However, how the reservoir storage capability will respond to climate change has hardly been considered. Previous eco-friendly 
reservoir storage requirement are generally derived from observed or synthetic flows and have rarely been determined by future flows under climate change $[5,7,11,12,13]$. So it is necessary to incorporate future climate change into reservoir storage capacity design to avoid or at least alleviate the negative impacts of dams on river ecosystem under future climate change.

The primary goal of this study is to explore the general behavior of water supply reservoirs with different storage capacities balancing both the human and ecological requirements for water under future climate change. A second goal is to provide a framework for the evaluation of different types of environmental flow requirement scenarios that lead to the most favorable tradeoffs between human and ecological requirements for water. The latter is evaluated considering different ecological requirement scenarios. Steps in the proposed model include: (1) weather generator module to generate feasible future climate conditions, (2) VMOD model as the hydrological simulation module to generate flows from those future weather conditions, and (3) reservoir optimization module to determine the optimal reservoir storage capability to deal with climate change under different ecological requirement scenarios.

\section{Methodology}

Weather generator module. General circulation models (GCMs), which describe atmospheric processes by mathematical equations, are one of the most important tools for studying the impact of climate change. Statistical downscaling aims to derive empirical relationships that transform large-scale features of the GCM (like precipitation and temperature) to regional-scale variables. Smooth support vector machine (SSVM) is used to predict climate change impact in this paper.

Hydrologic simulation module. Various climate conditions obtained using GCMs are used as input into the hydrologic model in order to further assess the impacts of climate change on local conditions in a basin. VMOD (Visual MODFLOW) distributed hydrological model is used to simulate the annual runoff corresponding to future climate change scenario in the Tang River basin.

Ecological requirement Scenarios. We used the most commonly used e-flow allocation scenarios:

Scenario 1. No water release for environmental requirement.

Scenario 2. Fraction of Inflow (FOI)

A fraction of the reservoir inflow is released as e-flows. The fraction is defined from 0.1 to 0.9 , so this scenario includes nine policies (from $\mathrm{FOI}=0.1$ to $\mathrm{FOI}=0.9$ ).

Scenario 3. Fixed Minimum Flow (FMF)

According Tennant method [14], we chose $10 \%$ of average daily flow (ADF) for dry season and $30 \%$ for the wet season.

Scenario 4. Flow Components (FC)

This scenario follows the Scenario 3, with one exception: it attempts to provide occasional high-flow releases. Herein, flows are considered to be a high flow if they fall above the $75^{\text {th }}$ percentile of all flows. After several high flow events have occurred in a year, no further high flow releases are required. There are three high flow events at least in each policy.

Scenario 5. Four-period release approach (FP)

The flows are divided into four periods and e-flows for each of the four basic flow periods are shown as follow [15]: i) Floods: The 1.5-year flood is used as an estimate of the bankfull discharges (bd) and the bd is released in flood period for e-flow; ii) Base flows: This period is same with the Scenario 2 (Fixed Minimum Flow). The 10\% ADF for the base flow in dry seasons, and 30\% ADF for the wet season base flow is used; iii) Extreme low flows: The inflow of reservoir is released as the e-flow; iv) High-flow pulses: all high flow events are released.

Reservoir optimization model. Reservoir operating rule curves (RORCs) are the most commonly used tools for directing reservoir operation. The operating rules include three curves: upper limit, lower limit and critical limit. A typical RORC is shown in Figure 1. The upper limit curve, which is defined during the reservoir design level by means of simulations, has not been changed in this paper, while the lower and critical limit curves will be optimized. Each of the two curves can be described by 
six parameters: two describe the high and low storage level zones $\left(X_{1}\right.$ and $X_{2}$ for the lower limit curve, and $X_{3}$ and $X_{4}$ for the critical limit curve), and the other four describe the initial and ending times of the linear transition zones between the high and low storage levels $\left(T_{1}, T_{2}, T_{3}\right.$ and $T_{4}$ for the lower limit curve, and $T_{5}, T_{6}, T_{7}$ and $T_{8}$ for the critical limit curve).

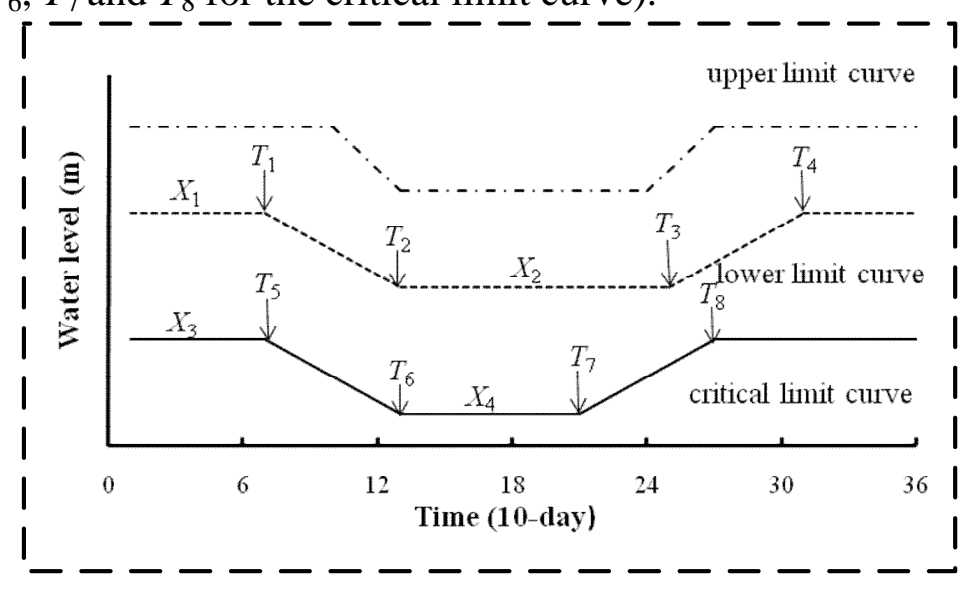

Figure 1. Typical reservoir operating rule curves.

To gain the RORCs (variables $X_{i}(i=1,2,3,4), T_{j}(j=1,2, \ldots, 8)$ ) and RSC with the e-flows allocation considered, the reservoir operation objective and constraints are designed as following. The basic structure of the reservoir operations model is described by a simple mass balance equating the change in storage to the difference between inflow and outflow

$$
S_{i}-S_{i-1}=I_{i}-\left(W_{i}+M_{i}\right)
$$

where $S_{i}$ is the reservoir storage at end of period $i ; M_{i}$ is the mass of water diverted from reservoir to water supply uses during period $i ; W_{i}$ is the water release from reservoir during period $i$; and $I_{i}$ is inflow to reservoir during period $i$ (Cardwell et al., 1996).

At each storage ratio, the objective is designed to maximize water supply reliability and the objective function is shown as:

$$
R=\max (S I)
$$

where $S I$ is water supply reliability, $S I=$ (the actual water supply)/( the planned water supply).

Subject to the following constraints for $X_{i}$ and $T_{j}$ as follows:

$$
\begin{aligned}
& \text { MAXLEVEL }>X_{1}>X_{2} \\
& \text { MAXLEVEL }>X_{1}>X_{3} \\
& X_{2}>X_{4}>\text { MINLEVEL } \\
& X_{3}>X_{4}>\text { MINLEVEL } \\
& 1 \leq T_{1}<T_{2}<T_{3}<T_{4}<36 \\
& 1 \leq T_{5}<T_{6}<T_{7}<T_{8}<36
\end{aligned}
$$

where MAXlevel is the maximum allowable storage level; MINlevel is the minimum admissible storage level.

\section{Study area}

Tanghe Reservoir is on the upper reach of Tang River in China. The dam was closed in 1969. It is a daily regulated multipurpose reservoir. The drainage area for the reservoir is $1,228 \mathrm{~km}^{2}$. The reservoir valves' release capability is $282 \mathrm{~m}^{3} \mathrm{~s}^{-1}$ and the spillway capability is $2713 \mathrm{~m}^{3} \mathrm{~s}^{-1}$. The reservoir is used for flood control as well as domestic and industrial water supply. It provides water $182.6 \times 10^{6} \mathrm{~m}^{3} / \mathrm{yr}$. 


\section{Results and discussion}

Future inflow character analysis. The validated SSVM downscaling model is used to downscale the future climate change scenario simulated by GCMs. This means that the large-scale predictor variables derived from A2 scenario of CGCM2 is used as input of SSVM downscaling model. Daily precipitation, daily mean, maximum and minimum temperatures are downscaled by SSVM for following nine future periods, namely 2010s (2011-2020), 2020s (2021-2030), ..., 2090s (2091-2100). The downscaled precipitation and temperature data are input of VMOD model to simulate the annual runoff corresponding to future climate change scenario in the Tang River basin. The simulated results of Tang River hydrological station is summarized in Table 1. Table 1 lists the relative changes of mean annual run-off in some hydrological stations. For example, under A2 scenario, the change rate of average daily flow in Tang River hydrological station will be about $1.5 \%$, $-1.11 \%$, and $-36.31 \%$ for the $2020 \mathrm{~s}, 2050 \mathrm{~s}$, and $2080 \mathrm{~s}$, respectively.

Table 1 The simulated results of Tang River hydrological station under the A2 scenarios of CGCM2

\begin{tabular}{|c|c|c|c|c|c|c|c|}
\hline \multirow{3}{*}{$\begin{array}{l}\text { Hydrological } \\
\text { station }\end{array}$} & \multicolumn{7}{|l|}{ CGCM2 } \\
\hline & \multirow{2}{*}{ Current years } & \multicolumn{6}{|c|}{ Future years } \\
\hline & & $2010 \mathrm{~s}$ & Change rate & $2020 \mathrm{~s}$ & Change rate & $2030 \mathrm{~s}$ & Change rate \\
\hline \multirow{5}{*}{ Tang River } & \multirow[t]{5}{*}{6.03} & 6.06 & 0.54 & 6.13 & 1.59 & 4.88 & -19.08 \\
\hline & & $2040 s$ & Change rate & $2050 \mathrm{~s}$ & Change rate & $2060 \mathrm{~s}$ & Change rate \\
\hline & & 4.15 & -31.12 & 5.96 & -1.11 & 3.60 & -40.24 \\
\hline & & $2070 \mathrm{~s}$ & Change rate & $2080 \mathrm{~s}$ & Change rate & $2090 \mathrm{~s}$ & Change rate \\
\hline & & 3.37 & -44.12 & 3.84 & -36.31 & 4.05 & -32.87 \\
\hline
\end{tabular}
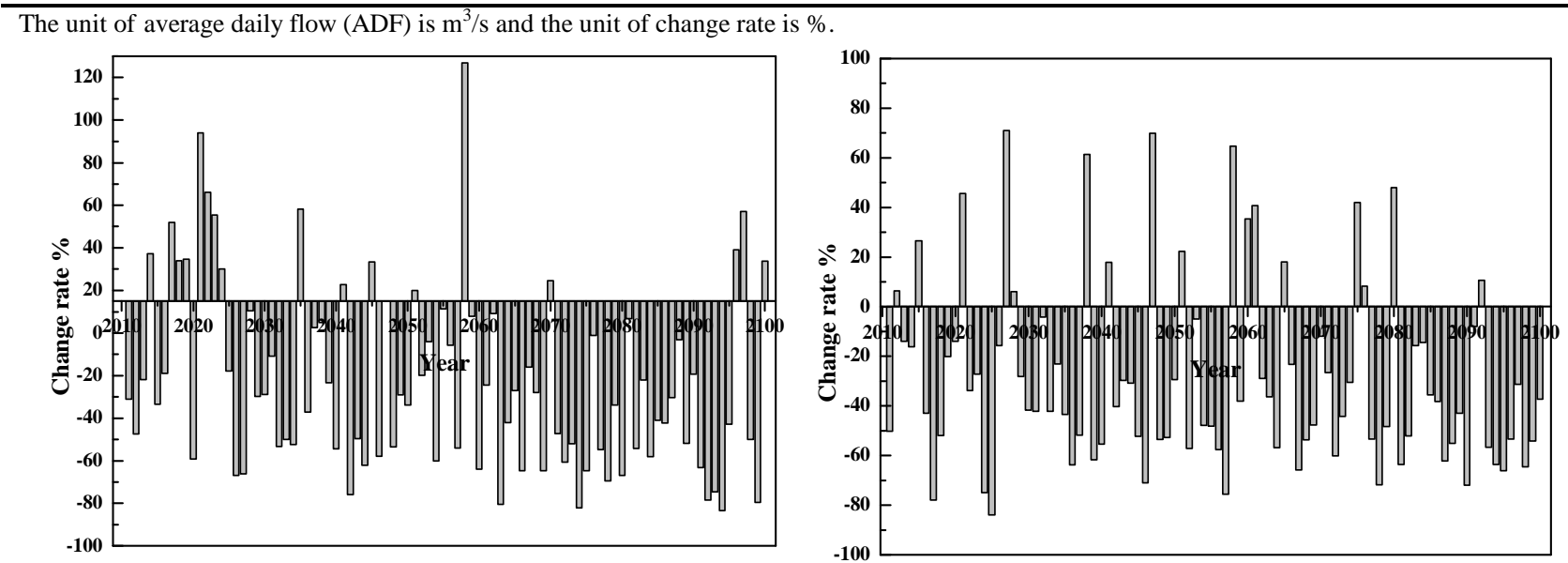

Figure 2 The simulated results of Tang River hydrological station under the A2 scenario of CGCM2

Relations between different storage ratios and water supply reliability. Figure 3 shows the maximum water supply reliability under the five different e-flow release scenarios (20 policies), along with different storage ratios. It is can be seen that the water supply reliability $\mathrm{R}$ is increased as reservoir storage ratio increasing. However, when the storage ratio is higher than 2 , the water supply reliability $\mathrm{R}$ will maintain the same even decrease. We can conclude that a high water supply reliability $\mathrm{R}$ could not always increase the performance of reservoir water supply. That is to say that the storage of reservoir is not the larger the better. 

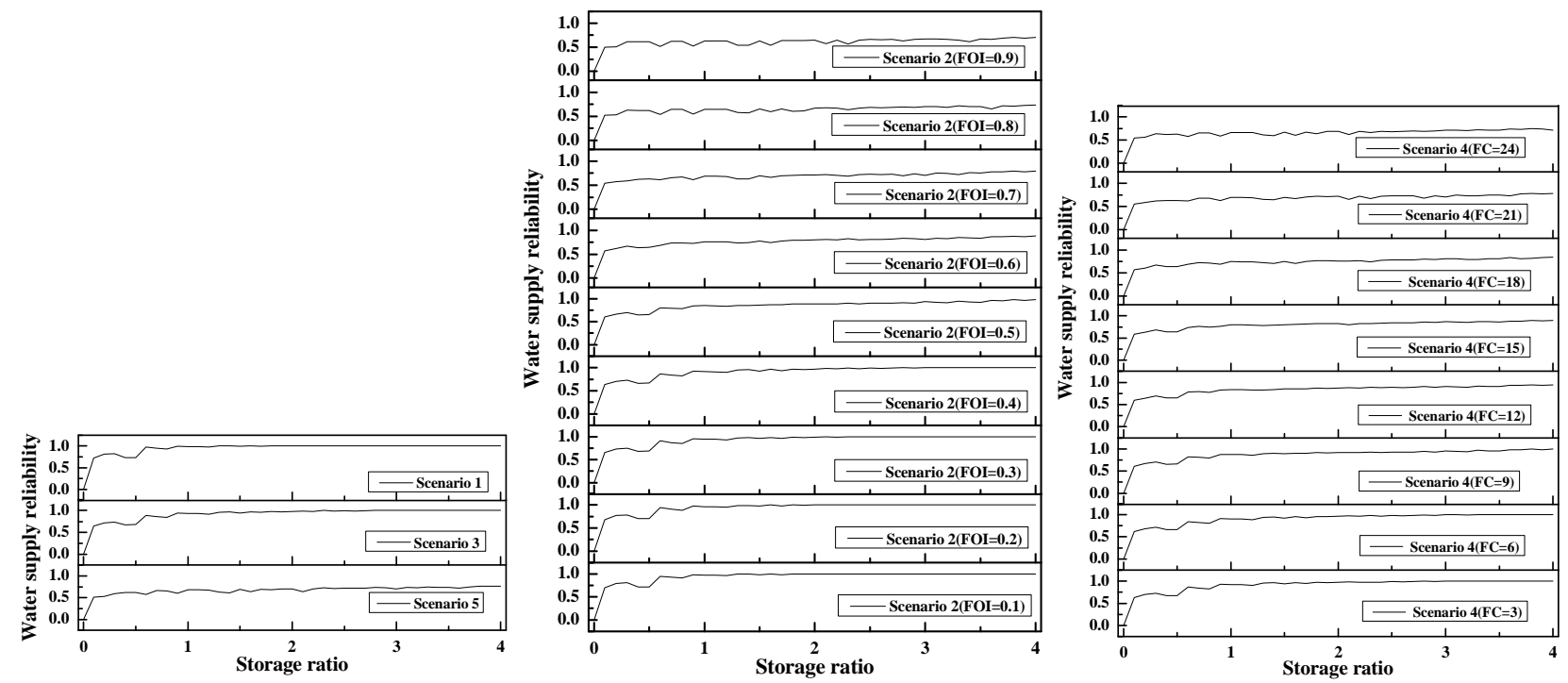

Figure 3 The storage relationship between different storage ratios and water supply reliability for various e-flow scenarios

Relations between different storage ratios and flow regime alteration. The overall flow regime alteration curves corresponding to five e-flow scenarios are shown in Figure 4. Before storage ratio $=$ 1.5 , the total flow regime alterations is shown in an increasing trend along with the increase fraction of storage ratio. Later, with the increase of storage ratio, it presents a decrease trend. This demonstrates that a large reservoir might be corresponding to a low flow regime alteration. That is because the large have more water resource which can be allocated to the ecosystem with fixed water supply demand.
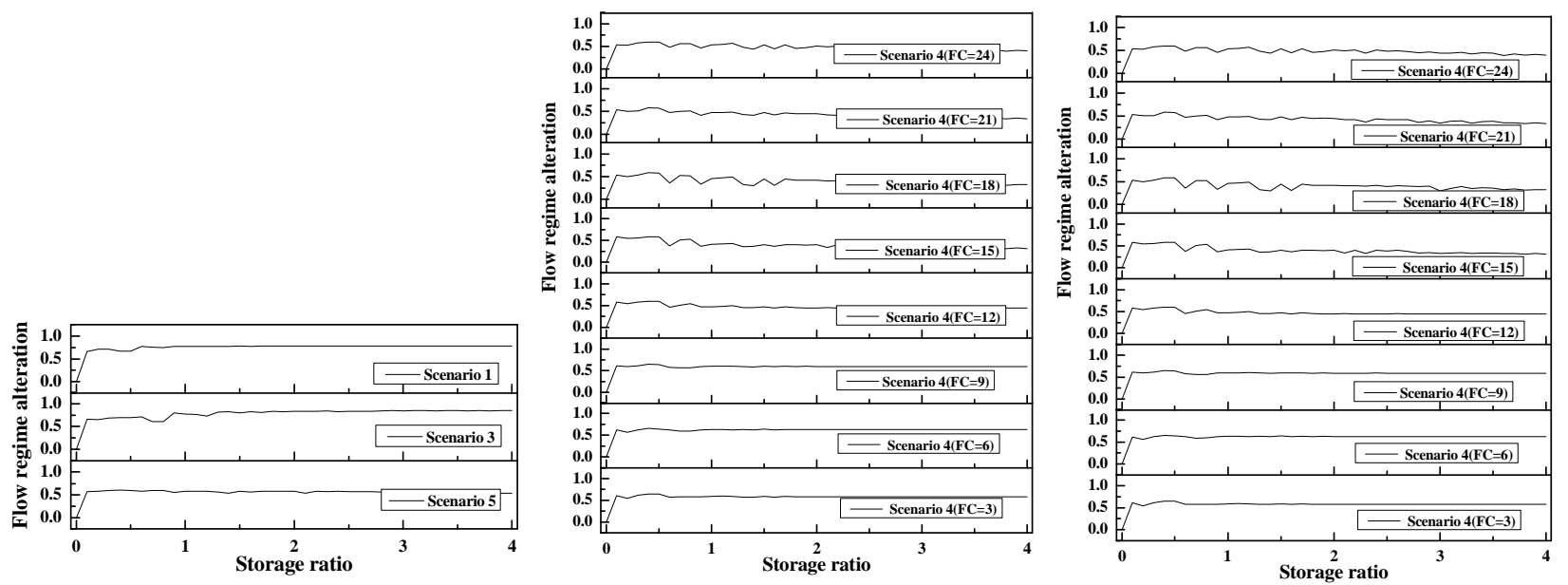

Figure 4 The relationship between different storage ratios and degree of flow regime alteration for various e-flow scenarios

\section{Conclusions}

In this study, a simple case study documents that the choice of different reservoir storage ratios could affect both water supply reliability and flow regime alteration. Overall, a longer storage ratio will not always lead to higher water supply reliability. Meanwhile, adding storage ratio can reduce the influence of reservoir construction on e-flow requirements to some extent. 


\section{Acknowledgements}

This research was supported by the National Key Research Program of China (no. 2017YFC0405903), National Key Research Program of China (no. 2016YFC0502806), National Natural Science Foundation of China (no. 51439001), and the National Science Foundation for Innovative Research Group (no. 51421065).

\section{References}

[1] Harman, C., Stewardson, M., 2005. Optimizing dam release rules to meet environmental flow targets. River Research and Applications, 21(2), 113-129.

[2] Suen, J.P., 2011. Determining the ecological flow regime for existing reservoir operation. Water Resources Management, 25(3), 817-835.

[3] Babel, M.S., Dinh, C.N., Mullick, M.R.A., et al., 2012. Operation of a hydropower system considering environmental flow requirements: a case study in La Nga river basin, Vietnam. Journal of Hydro-environment Research, 6(1), 63-73.

[4] Tharme, R.E., 2003. A global perspective on environmental flow assessment: emerging trends in the development and application of environmental flow methodologies for rivers. River Research and Applications, 19(5-6), 397-441.

[5] Suen, J.P., Eheart, J.W., 2006. Reservoir management to balance ecosystem and human needs: Incorporating the paradigm of the ecological flow regime. Water Resources Research, 42(3).

[6] Richter, B.D., Thomas, G.A., 2007. Restoring environmental flows by modifying dam operations. Ecology and Society, 12(1).

[7] Vogel, R.M., Sieber, J., Archfield, S. A., et al., 2007. Relations among storage, yield, and instream flow. Water Resources Research, 43(5).

[8] Yin, X.A., Mao, X.F., Pan, B.Z., et al., 2015. Suitable range of reservoir storage capacities for environmental flow provision. Ecological Engineering, 76, 122-129.

[9] Lazzaro, G., Botter, G., 2015. Run-of-river power plants in Alpine regions: Whither optimal capacity?. Water Resources Research, 51(7), 5658-5676.

[10] Yin, X.A., Mao X.F., Pan B.Z., et al., 2015. Suitable range of reservoir storage capacities for environmental flow provision. Ecological Engineering, 76, 122-129.

[11] Anagnostopoulos, J.S., Papantonis, D.E., 2007. Optimal sizing of a run-of-river small hydropower plant. Energy Conversion and Management, 48(10), 2663-2670.

[11] Shiau, J.T., Wu, F.C., 2004. Assessment of hydrologic alterations caused by Chi-Chi diversion weir in Chou-Shui creek, Taiwan: Opportunities for restoring natural flow conditions. River Research and Applications, 20, 401-412.

[12] Jager, H.I., Smith, B.T., 2008. Sustainable reservoir operation: can we generate hydropower and preserve ecosystem values?. River Research and Applications, 24(3), 340-352.

[13] Shiau, J.T., Huang, C.Y., 2014. Detecting multi-purpose reservoir operation induced time-frequency alteration using wavelet transform. Water Resources Management, 28(11), 3577-3590.

[14] Tennant, D.L., 1976. Instream flow regimens for fish, wildlife, recreation and related environmental resources. Fisheries, 1(4), 6-10.

[15]Yin, X.A., Yang, Z.F., Petts, G.E., 2011. Reservoir operating rules to sustain environmental flows in regulated rivers. Water Resources Research, 47, W08509. 